\title{
Business Innovation with Enterprise Architecture
}

\author{
Yaw Marfo Missah, PhD \\ KNUST \\ Computer Science \\ Ghana-Kumasi
}

\begin{abstract}
Enterprise Architecture serves as a business concept for optimization and facilitation of internal business processes along with technical aspects of business. Despite the evident benefits, the integration of architecture may cause detrimental effects and additional risks for any perspective company. Organizations occupied in innovation business are actively incorporating EA principles today, taking additional risks from integration of new business ideology within the formalized IT field. Current research examines the issues of EA integration, factors of success and potential failures, compliance between business architecture and technical architecture, and evaluates the mechanisms of proper integration of EA in innovating business.
\end{abstract}

\section{General Terms}

Business Innovation, Enterprise Architecture

\section{Keywords}

Enterprise architecture, business architecture, technical architecture, optimization, integration

\section{INTRODUCTION}

Almost all business organizations and enterprises build their activity on the base of so-called structured framework, while its foundations comprises of company's goals and main processes. As a rule, organizations working within Enterprise Architecture (EA) concept, i.e. specialized vision of business processes' formalization, are capable to positively affect the quality of organization structure's building and its relation to central business processes and strategic goals of organization. Thus, due to EA any company becomes more integral, flexible, stronger, consistent, and competitive. Of course, the results of EA building and maintenance do not come suddenly, although they have a crucial purpose for strategic course of organizations, increasing possibility of final success. Innovation business incorporates risks and threats at full, while EA ideology may sufficiently enhance the perspectives and working efficiency of business processes within the innovating organization, improving the quality of proposed innovations as well. Evidently, current research work indicates that the success of innovating business depends on the government of enterprise architecture elements and disciplines which provide special relation between business strategy and innovation business processes.

\section{ENTERPRISE ARCHITECTURE: DEFINITION AND RELATION TO INNOVATION}

What is EA in its essence? EA is a generalized and multidirectional vision of business organization that pursues shortterm and long-term goals of business development on the basis of strategy, mission, working capacities, available resources, and perspectives. Viewing EA in dynamics, it is possible to assert that, formally, architecture is a logical action plan and coordination of business processes necessary for transformation of architecture's principles into practical longterm perspective of business activity [8]. Unsurprisingly, innovating organizations develop their business on the base of coordination of different business processes: at the end of the day, none of innovations would have been realized today unless the coordination of innovation IT department with financial, supply, and engineering units within the organization. Indeed, EA helps innovating organization to facilitate its innovating potential.

Modern innovating organizations, specifically in the field of Information Technologies (IT), make everything possible to adapt and develop their business within the frames of identified business structure. Obviously, designing of EA inside innovating organization does not exactly mean that the structure and business concept will be utilized effectively. Nevertheless, EA may serve as critically useful enabler for enhancing and stabilizing the business value of innovation. Most notably, almost all organizations deal with business architecture concept - unfortunately, they are either unaware of it, or the architecture remains non-formalized and nonoptimized. Small innovation businesses barely need EA as their indicator of business perspectives. However, if business is growing, then the architecture must be formalized, at least on the level of basic models such as Zachman model [11]. Big innovating organizations are in highest need of EA: architecture of business processes becomes the 'skeleton', while all internal innovating business processes are supported by skeleton's load-bearing constructions. The role of business architect refers the creation of integral vision of innovation business: in other words, business architect will be obliged to coordinate current aspects of organization with future potential aspects of business. In some sense, the practice of EA formalization is not just a technology or a set of knowledge, it rather business art, an ability to forecast the development of innovation business in long-term perspective.

\section{POSSIBILITIES AND RISKS OF IMPLEMENTING EA IN INNOVATING BUSINESS}

\subsection{Opportunities}

In fact, the efforts concerning the building of EA comprised of business models are compensated very quickly because EA's implementation provides business organization with certain opportunities. In this sense, business models are viewed as dynamic flow of events related to business and various functions of business and its units. The possible output from implementation of business models within EA has been investigated and studied throughout decades. 
According to specialists, the main problem is to persuade company's owners to use the advantages of EA's integration for optimization of formalized business models. As a rule, benefits of EA's integration are stemming from two 'grounds': additional opportunities for business expansion and cost reduction. For instance, the creation and implementation of business models in innovation business, including the factors of investments and expenses, provides organizations with cost reduction on $10 \%$, even without any radical changes of business [10]. Evidently, the modeling of business processes' alternative directions helps innovating organizations in saving up to $20 \%$ financial resources. In general, EA concept offers 'specific language of communication' to innovating organizations: it assists managers of different departments in correct collaboration and coordination of their business actions, minimizing the costs on development and realization of innovation. For instance, EA contributes to appropriate communication between business architects and IT-specialists, facilitating the optimization of principal business models.

\subsection{Risks}

Nevertheless, there are also some risks associated with integration of $\mathrm{EA}$ in innovation sphere. In relation to innovation practices in IT the first risk is a development of extremely cumbersome architecture which rather delays the productivity and output of business models. Innovation practices are strictly adhered to terms of development and optimization, while another "burden", i.e. severe compliance with structured business models, undermines the integral independence of innovating business. Problems with general EA adoption are also relevant: if innovating organization did not use formalized business models before, there are doubts over sudden success of EA integration today.

\section{PROMOTION OF EA IN INNOVATING ORGANIZATIONS}

\subsection{Practical example}

How does it work in practice and how could EA promote business innovation? For instance, we can take IT department of IGI Company which is occupied in development of innovations in the sphere of supply chains. The pivot of company's EA is innovative governance of supply chains. With integration of EA the entire construction of company's business system has become full-fledged and firm. There is a model of strategic goals on the top level of IGI's infrastructure; meanwhile quality and velocity criteria are fundamental within this model. Quality includes the value of innovation in supply industry, well-timed delivery, accuracy of documentation, etc. Velocity means the ability of company to satisfy the needs of customers as soon as possible. Evidently, IGI looks for balance between the level of supplies and level of demand [5]. In complex, all strategic goals predetermine the innovating business and activities of company, including the development of novel types of purchases, innovative and optimized transportation, and advanced form of storage.

Accordingly, each activity refers to structured business process in terms of EA model. The Supply Chain Operations Reference Model serves as a basis for given business architecture. Noteworthy, IGI creates all preconditions for further intensive development and improvement of model. According to experts, IGI started the formulation of the EA on the base of Zachman's model. On the different levels of detailed elaboration the model provides formal answers for different functions of organizational business. Therefore, business architecture incorporates the functional structure of organization including a set of business processes which use single data and meet the requirements of EA [2]. The low level of functional architecture comprises of regulations and guidelines. In this sense, business processes formulate requirements towards automation, and then these requirements serve as a basis for development of system architecture which describes infrastructure and role of supply innovations within it. Innovating activity directly correlates with system architecture and business architecture, while strict requirements on each level of detailed elaboration contribute to inseparable realization of innovating project in terms of company's strategic model.

\subsection{Common ways and mechanisms of EA integration in innovation business}

As it was mentioned above, business models play essential role in the process of EA's development. In this sense, the task of innovating organizations is to provide smooth relation between key business processes and IT-architecture. Fortunately, innovation business models can be realized in numerous ways because within innovation business these models are descriptive, executable, qualitative, quantitative, etc. Therefore, they can be promoted as exclusively on the level of business for optimization of all processes as specifically for optimization of mutual relations between business practitioners and IT-specialists in the area of innovations. It is possible to underline that promotion and development of EA principles in innovating organization starts with designing of high-level and high-priority processes of organization. The initial phase is the identification of business processes' classes, i.e. the groups of processes which include the similar business activities [9]. For instance, if organization develops IT innovation for banking area of business, there can be the following class of business processes: collection of information pertaining to the banking systems, gathering of facts relating to their optimal characteristics, the analysis of secondary materials of research, identification of information distribution, methods of assessment, administration of previous systems, etc.

When the classes of business processes are defined, it is necessary to make specialized optimization practices. First, architects identify critically important business processes within innovating organization. In fact, those processes which specifically impact the organization's ability to realize innovating mission and meet innovating strategy, goals, and functions can be regarded as key and significant for inclusion into framework of EA. In innovation business, the following processes have also special meaning for optimization of EA [7]:

-processes which provide novel opportunities for business; for instance, new technologicallyequipped supply chain, as it was described above;

-current processes which hamper the development and progress of innovating vision and directory, or, they become main source of customers' discontent;

-processes directly oriented on cost-saving within innovation environment.

Indeed, such processes must be framed within EA in the first place. When the processes are categorized, it is crucial to examine the links between selected processes and business strategies, organization's driving forces and critically important factors of success. Specialists recommend using the 
matrix of interdependencies for this purpose [5]. Thus, every element of matrix will be evaluated by qualitative value under the principle "relevant/irrelevant", or improvised assessment scale. Afterwards, architects are able to build the high-level models for key business processes and appoint responsible performers. The last step is the identification and registering of information objects' categories on the level of documentation. In this sense, the number of identified highlevel business models as well as understanding of relations with critical factors helps managers to control the innovation activities and exploitation of IT resources.

\section{IMPACTS OF EA INTEGRATION IN INNOVATING BUSINESS}

Described mechanisms and frameworks in innovation business do not set the methodologies for generation of solutions within EA. They serve as a way to understand the necessity of potential shifts or modifications, necessity to design their stages, or align the system components, etc. Specifically generalized schemes and models of EA give an opportunity to control the integrity and consistency of formalized architects, regulate their characteristics of innovation projects, or examine new characteristics, and assign new positions that require additional analysis. Couger, also found that generalized methodologies, tools, and procedures of architectural modeling do not provide a business architect with proper solution, but rather guide his/her job, helping in documentation and analysis of EA's complicated structure[4]. Therefore, most business practitioners are trying to develop homogenous forms and methods of building EA within innovation business. For instance, such methodology may concern the integration of tracking system that observes the flow of investments in both directions. In this sense, EA allows business practitioners to control the activity of IT department and business processes related to investments almost simultaneously. However, such solutions require the highest level of elaboration and big number of alternative options with proper methodologies of implementation. Johnson \& Eksted, have identified that the methods Business Process Reengineering (BPR) and Business Process Testing (BPT) can be successfully used as a core for EA of innovation business: thus, business processes become more flexible and can be evaluated in terms of entire architecture [7]. For instance, if some process and procedure within innovation project gets changed or shifted, EA allows practitioners to respond to transformation adapting and adjusting other elements of EA. It can be extremely helpful for business stability because such adaptation minimally affects the work of IT department.

At the same time, some impacts of EA integration in innovating business lead to additional difficulties in business. For instance, it is appeared that building of EA under one methodology requires the addition of other adjoining methods of modeling. Cash, Earl and Morison, have noticed that the focusing on business processes in relation to IT-system usually results in poorer attention to maintenance of databases [3]. Therefore, the methodology of data integration is necessary as well, although it requires additional time and resources. The projecting of EA requires consistency from both business practitioners and IT specialists; meanwhile, the recent researches have proven the fact there is still critical misunderstanding between both links of EA [11]. Thus, integration of EA implies the strong compatibility of technical and business processes. However, the problem of incompatibility is typical for EA modeling practices. At the same time, Callegard and Handling, state that a possible negative consequence is the risk of not being able to keep up with the constantly developing business strategy of the company while working with their framework: "the maturity level of the company, i.e. how ready they are for using Enterprise Architecture, affects the ability of the company's creative and innovative processes" [2]. Without having innovation and creativity potential in terms of EA, the innovating organization will not be able to implement any changes over business processes.

\section{COMPANIES FAIL TO IMPLEMENT INNOVATION THROUGH EA}

It is important to underline that governmental sector is most 'vulnerable' area in relation to risk and inefficient business solutions, including innovating directions. Most experts suppose it happens because of lack of proper strategy and business architecture. According to the reports of the U.S. Center for Technology in Government, almost 70-80\% of failed IT-projects refer to governmental sector, comparing to similar 54\% of failures for other industries [9]. Approximately third part of failures indicates about disadvantages of EA modeling and integration. Hoogervorst, claims, with referring to the data of Office of Management and Budget, that 17 federal agencies among 26 examined organizations involved into 1400 IT-projects with particular innovative direction were found in category of high risk; more than 120 federal programs on business innovations were not capable to show any sign of efficiency; and $20 \%$ of them were considered as totally inefficient [6]. According to the experts, the reasons behind failure of innovation's integration were inadequate evaluation of developed decisions concerning innovations. In addition, some analysts permit that innovating federal officials were simple unaware of effect and impact of combination of EA business models and standardized practices of IT development. In other words, practitioners had strictly subjective attitude on the work of innovating organization in terms of adapted EA. Biswas, examining the trends over integration of Enterprise Architectures in Indian IT sector, found two critical causes of failures, which can be compatible with innovation practices as well [1]: 1) incorrect selection of methodologies tools for integration and adaptation; 2) and incorrect integration of selected EA solution. As a result, almost 80 IT companies of India failed to realize their innovation concepts in terms of EA. These two critical errors were formed on the base of the following operational flaws: -the project was invested prior to formulation of basic
requirements;

-the IT innovation was developed without involvement of future customers;

-the IT innovation was designed without accounting to real terms of work;

-the IT innovation was elaborated without concordance over other processes and models;

-the IT project had a short budget cycle of project;

-restricting capabilities of integrated EA.

\section{CONCLUSION}

In most cases, Enterprise Architecture is a good tool for arrangement of formal agreement between business practitioners and IT performers. For business practitioners is a 'mirror' of business processes within the organization, providing opportunities for business's modification and coordination. For IT performers is a 'yardstick' of compliance 
between the requirements and received outcomes. As researching analysis shows, innovating businesses and organizations may successfully operate their innovation projects with more synergy and flexibility under the influence of structured EA. Additionally, current research has provided pitfalls of incorrect integration of EA in innovating organizations to avoid similar experience in the future.

\section{REFERENCES}

[1] Biswas, P.K. (2011). Networks of small enterprise, architecture of governance and incentive alignment: some cases from India. AI \& Society, 26(4), 383-391.

[2] Callegard, C. \& Handling, M. (2011). Enterprise Architecture- How does it support innovation? University of Boras, Sweden.

[3] Cash, J.I., Earl, M.J., \& Morison, R. (2008). Teaming Up to Crack Innovation and Enterprise Integration. Harvard Business Review, 3-15.

[4] Cougar, D.J. (1996). Creativity \& Innovation - in Information Systems Organizations. Danvers, MA: Boyd $\&$ Fraser.

[5] Ham, W.H. \& Shankararaman, V. (2007). Enterprise Architecture and Integration Methods, Implementation, and Technologies. Hershey, PA: Idea Group Inc.
[6] Hoogervorst, J.A.P. (2004). Enterprise architecture: Enabling integration, agility and change. International Journal of Cooperative Information Systems, 13 (3), 213 233 .

[7] Johnson, P. \& Eksted, M. (2007). Enterprise Architecture: Models and Analyses for Making Information Systems Decision Making. Lund, Sweden: Studentlitteratur AB.

[8] Land, M. Proper, E., Waage, M. Cloo, J., \& Steghusis, C. (2008). Enterprise Architecture: Creating Value by Informed Goverance. New York, NY: Springer.

[9] Ross, J.W., Weill, P., \& Robertson, D. (2006). Enterprise Architecture As Strategy: Creating a Foundation for Business Excution. Boston, MA: Harvard Business Review Press.

[10] Sinur, J. (2002). Business Models: The Architecture That Pays for Itself. Gartner Report.

[11] Zachman, J.A. (1996). Enterprise Architecture: The Issue of The Century. Database Programming and Design Magazine, 31 (3), 2-13. 